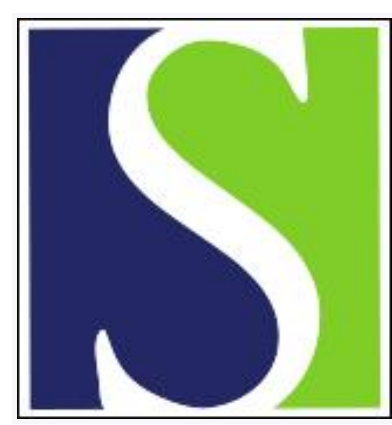

Scand J Work Environ Health 1995;21(3):223-228

https://doi.org/10.5271/sjweh.31

Issue date: Jun 1995

Prevalence of microfungi in Finnish cow barns and some aspects of the occurrence of Wallemia sebi and Fusaria

by Hanhela R, Louhelainen K, Pasanen A-L

Key terms: airborne spore; bedding material; farm building; feeding material; fungal flora

This article in PubMed: www.ncbi.nlm.nih.gov/pubmed/7481610

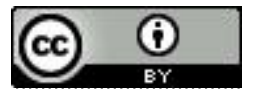




\title{
Prevalence of microfungi in Finnish cow barns and some aspects of the occurrence of Wallemia sebi and Fusaria
}

\author{
by Rauno Hanhela, MSc, ${ }^{1}$ Kyösti Louhelainen, MSc, ${ }^{2}$ Anna-Liisa Pasanen, PhD ${ }^{3}$
}

\begin{abstract}
Hanhela $R$, Louhelainen $K$, Pasanen A- $L$. Prevalence of microfungi in Finnish cow barns and some aspects of the occurrence of Wallemia sebi and Fusaria. Scand J Work Environ Health 1995;21:223-8.

Objectives The occurrence of microfungi in the air and in feeding and bedding materials was studied on 32 Finnish dairy farms.

Methods Air samples for determining viable and total spore concentrations were collected on membrane filters and with a cascade impactor. Genera of mesophilic, xerophilic, and thermophilic fungi were identified in four culture media. Total spore counts were done with the aid of an epifluorescence microscope. To identify fungal flora in agricultural materials, feeding and bedding material samples were also taken from the farms.

Results The airborne spore concentrations varied for viable mesophilic, xerophilic, and ther mophilic fungi from $10^{1}$ to $10^{7}$ colony-forming units per cubic meter, and for total spores from $10^{5}$ to $10^{7}$ spores per cubic meter. Aspergillus, Penicillium, Cladosporium, Absidia species, Wallemia sebi and yeasts were the predominant fungi in the air, as well as in the material samples.

Conclusions In general, the airborne spore concentrations were high although the variation in the concentrations of different fungal groups was large between the farms. Along with using new growth media, two fungi whose prevalence was earlier poorly known in Finland were detected. W sebi proved to be the most abundant xerophilic fungi in the air and hay samples, while Fusarium spp were very common in grain and straw but rare in air.
\end{abstract}

Key terms airborne spores, farm buildings, feeding and bedding materials, fungal flora.

It is well-known that exposure to actinomycete and fungal spores can cause different respiratory symptoms and diseases among farmers. The airborne microbial concentrations and composition of microbial flora have been widely studied in agricultural work environments. In farm buildings, viable spore concentrations have been reported to vary between $10^{2}$ and $10^{11}$ colony-forming units $(\mathrm{cFu}) \cdot \mathrm{m}^{-3}$ depending on the type of farming (dairy, pig, or poultry farming) and phases of work $(1-8)$. In the studies, the species Aspergillus (eg, A glaucus group and A fumigatus), Penicillium, Cladosporium, Rhizopus, Mucor, Paecilomyces, Alternaria, Absidia, Botrytis, and Scopulariopsis and yeasts have been observed to be the most common airborne fungi. Fungal spores originate from different sources in the agricultural environment. Laboratory and experimental studies have indicated that the same fungal species that are identified in hay, grain, straw, silage, wood shavings, and sawdust are also de- tected in the air samples collected during the handling of the same materials $(6,9-15)$.

Traditionally, viable spore concentrations in work environments have been determined with sampling and counting methods based on the cultivation of microorganisms under certain conditions (eg, collection with slit samplers or cascade impactors). For highly contaminated occupational environments, the use of viable counting techniques has been criticized because of the short sampling times, a risk of overloaded agar plates, and a consequent large variability in concentrations between samples $(6,11,16)$. In addition, viable spores or culturable spores, as a matter of fact, represent only a small part of the total airborne spores. However, both viable and dead spores can cause symptoms among occupants. Therefore, in recent years, direct epifluorescence, scanning electron and light microscope counting techniques have been developed for making the total spore count

1 Ministry of Labour, Occupational Safety and Health Division, Tampere, Finland.

2 Kuopio Regional Institute of Occupational Health, Kuopio, Finland.

3 University of Kuopio, Department of Environmental Sciences, Kuopio, Finland.

Reprint requests to: Dr Anna-Liisa Pasanen, University of Kuopio, Department of Environmental Sciences, PO Box 1627 , FIN-70211 Kuopio, Finland. 
$(5,6,11,17)$. However, the identification of microorganisms seems to be a problem with these methods, because it is solely based on differences in spore size, shape, and surface ornamentation. Thus cultivation is still the most reliable practice to identify fungal flora. On the other hand, the recovery of different species is strongly affected by growth media. Through the selection of various media, new aspects of the prevalence of fungal species can be revealed or even previously unknown species can be detected.

In Finland, the prevalence of airborne fungi in agricultural work environments has usually been investigated from air samples collected with a cascade impactor using malt-glucose-rose Bengal (HAGEM) agar for mesophilic and thermophilic fungi and $10 \%$ sodium chloride-malt extract (NaCl-MALT) agar for xerophilic fungi. Total spore concentrations have been previously reported only in a few studies $(5,18)$. In the present work, in addition to cascade impactor sampling, both viable and total spore concentrations were determined in cow barns with the CAMNEA (collection of airborne microorganisms on nucleopore filters, estimation and analysis) method on the basis of filter sampling and the analysis of spores through cultivation and direct counting with an epifluorescence microscope (17). In addition to the traditionally used growth media, fungi were also cultivated on 2\% malt extract (MALT) and dichloranglycerol (DG18) agars. Furthermore, the origin of different fungal genera was clarified by isolating fungi from feeding and bedding materials used in the cow barns.

\section{Materials and methods}

The study was carried out on 32 dairy farms, of which 16 were situated in Ostrobothnia and 12 in eastern, 2 in northern and 2 in central Finland. The barns were built in 1870-1991, and 15 buildings had been repaired during the last 18 years. Twenty-one barns were equipped with a mechanical exhaust ventilation system, and the rest had natural ventilation. The number of milking cows varied from 6 to 24. All of the farms used dried hay and grain, and in addition 31 farms used silage for feeding the cattle. On 30 farms, bedding materials, usually dried straw but on some farms also dried hay, peat, wood shavings and sawdust, were used.

The samples were collected on the farms in JanuaryApril 1993. In each barn, one filter sample (polycarbonate filter, diameter $37 \mathrm{~mm}$, pore size $0.4 \mu \mathrm{m}$, Nuclepore Corporation, Pleasanton, USA) at the flow rate of $2.01 \cdot \mathrm{min}^{-1}$ and two series of six-stage cascade impactor samples (model 10-800, Andersen Inc, Atlanta, USA) at a flow rate of $28.31 \cdot \mathrm{min}^{-1}$ were taken at the height of $1.5 \mathrm{~m}$ on a feeding passage as the farmers worked. The sampling times varied between 1.5 and $4 \mathrm{~h}$ for the filter samples and 42 and $106 \mathrm{~s}$ for the impactor samples. The corresponding air volumes were 177-531 1 and 20501 , respectively. One of the impactor samples was collected during or after the handling of dried hay, and the other was taken after the handling of bedding or other feeding materials. Filter sampling was started 15$60 \mathrm{~min}$ before the first impactor sampling, and it ended not later than 30 min after the second impactor sampling.

Viable and total spore concentrations from the filter samples were analyzed with the CAMNEA method described in detail elsewhere (17). Mesophilic and thermophilic fungi were cultivated on MALT agar and incubated at $25^{\circ} \mathrm{C}$ for $5-7 \mathrm{~d}$ and at $40^{\circ} \mathrm{C}$ for $3-4 \mathrm{~d}$, respectively. Xerophilic fungi were cultivated on DG18 agar (19) and incubated at $25^{\circ} \mathrm{C}$ for $5-7 \mathrm{~d}$. Both media contained $100 \mathrm{mg} \cdot 1^{-1}$ of chloramphenicol to prevent the growth of bacteria. To count the total number of spores with the CAMNEA method, the suspended particles from the filter samples were stained with acridine orange, and spores were counted with an epifluorescence microscope (17) without any separation of the fungal and actinomycete spores.

The impactor samples were collected on MALT and HAGEM (20) agars for mesophilic fungi, NaCl-MALT agar (21) for xerophilic fungi, and HAGEM agar for thermophilic fungi. The HAGEM and NaCl-MALT agars contained $35 \mathrm{mg} \cdot 1^{-1}$ of streptomycin to inhibit the growth of bacteria. The plates for different fungal types were incubated as has already been described. The viable spore counts were calculated by the positive hole correction method to take account of the probability that more than one spore was impacted into the same point on a collection medium (22). In both the filter and impactor samples, yeasts were counted separately, and fungal genera were identified with a light microscope. Viable spore concentrations were presented as colony-forming units ( $\mathrm{cFu}$ ) per cubic meter and the total spore concentrations as spores per cubic meter.

The feeding and bedding material samples that were handled during the air sampling were also collected on each farm. Fungal flora was identified from 41 hay, 26 grain, 21 straw, 10 silage, 8 sawdust or wood shaving, and 4 peat samples. The samples were weighed and homogenized in dilution water $\left(1 \mathrm{~g} \cdot \mathrm{l}^{-1}\right.$ of peptone, $0.01 \%$ of Tween 80 detergent) and shaken for $1 \mathrm{~h}$. From each, a dilution series was prepared, and suspensions were plated on MALT agar for mesophilic and thermophilic fungi and on DG1 8 agar for xerophilic fungi. In addition, a subsample of each material was strewn as such on agars to avoid a dilution effect and to determine also the fungal genera that are not predominant in the samples. The plates were incubated as mentioned previously. Only the composition of the fungal flora was recorded, but the spore concentrations were not determined from the samples. 


\section{Results}

The viable fungal spore and total spore concentrations measured on 32 farms are presented in table 1. The viable spore concentrations varied from $10^{2}$ to $10^{6}$ $\mathrm{cFu} \cdot \mathrm{m}^{-3}$ for mesophilic, $10^{3}-10^{7} \mathrm{cFu} \cdot \mathrm{m}^{-3}$ for xerophilic and $10^{1}-10^{5} \mathrm{cFu} \cdot \mathrm{m}^{-3}$ for thermophilic fungi, depending on the method and growth media. Total spore concentrations were $10^{5}-10^{7}$ spores $\cdot \mathrm{m}^{-3}$. The prevalence of the main fungi in the air samples is shown in table 2. The most common fungi were Aspergillus spp, especially the A glaucus group and A fumigatus, Penicillium spp, Cladosporium spp, yeasts, Acremonium spp, Wallemia sebi, Absidia spp, Paecilomyces spp and Mucor spp. Other fungal genera that were present in $<54 \%$ of the air samples and comprised $<4 \%$ of fungi were Acremoniella, Alternaria, Arthrobotrys, Aureobasidium, Botrytis, Dimargaris, Eurotium, Fusarium, Geotrichum, Gliomastix, Gonatorhodiella, Humicola, Hyalodendron, Monascus, Monocillium, Neosartorya, Olpitrichum, Papularia, Phialophora, Phoma, Rhizopus, Scopulariopsis, Staphylotrichum, Trichoderma, Trichothecium, Verticilliun, and Wardomyces.

The occurrence of fungi in the feeding and bedding materials is presented in table 3 . Some fungal genera, such as Penicillium, Aspergillus, Cladosporium, Rhizopus, Absidia and yeasts, were detected in nearly all of the material samples. On the other hand, some fungi occurred the most abundantly in certain materials, like

Table 1. Viable spore concentrations of mesophilic, xerophilic and thermophilic fungi and total spore concentrations in the air of 32 cow barns measured with CAMNEA (collection of airborne microorganisms on nucleopore filters, estimation and analysis and cascade impactor methods. (GM = geometric mean, $\mathrm{CFu}=$ colony-forming unit, $\mathrm{MALT}=2 \%$ malt extract agar, $\mathrm{HAGEM}=$ malt-glucose-rose Bengal agar, DG18 = dichloran-glycerol agar, NaCl-MALT $=10 \% \mathrm{NaCl}$-malt extract agar)

\begin{tabular}{lllll}
\hline Fungal group & \multicolumn{4}{c}{$\begin{array}{c}\text { Spore concentration } \\
\text { (cFu or spores } \cdot \mathrm{m}^{-3} \text { ) }\end{array}$} \\
\cline { 2 - 5 } & $\begin{array}{c}\text { Number } \\
\text { of } \\
\text { samples }\end{array}$ & & & Minimum Maximum \\
& & & & \\
\hline Mesophilic fungi & 32 & $5.7 \cdot 10^{4}$ & $6.5 \cdot 10^{3}$ & $1.7 \cdot 10^{6}$ \\
$\quad$ CAMNEA/MALT & 64 & $1.3 \cdot 10^{4}$ & 500 & $3.1 \cdot 10^{5}$ \\
Impactor/MALT & 64 & $2.0 \cdot 10^{4}$ & 200 & $3.5 \cdot 10^{5}$ \\
Impactor/HAGEM & & & & \\
Xerophilic fungi & 32 & $3.3 \cdot 10^{5}$ & $1.1 \cdot 10^{4}$ & $1.4 \cdot 10^{7}$ \\
$\quad$ CAMNEA/DG18 & 64 & $4.0 \cdot 10^{4}$ & $1.2 \cdot 10^{3}$ & $4.9 \cdot 10^{5}$ \\
Impactor/NaCI-MALT & & & & \\
Thermophilic fungi & 32 & 540 & 30 & $1.5 \cdot 10^{5}$ \\
CAMNEA/MALT & 64 & 470 & 20 & $9.1 \cdot 10^{4}$ \\
Impactor/HAGEM & & & & \\
Total Spores & 32 & $4.7 \cdot 10^{6}$ & $5.6 \cdot 10^{5}$ & $4.0 \cdot 10^{7}$ \\
CARNEA & & & & \\
\hline
\end{tabular}

Fusarium spp in grain and straw, W sebi in hay, Paecilomyces spp, Aureobasidium spp, and Trichoderma spp in wood shavings and sawdust, and Trichoderma spp in peat.

\section{Discussion}

A large variation in spore concentrations was observed between the air samples regardless of the sampling and counting methods. The spore concentrations varied from $10^{2}$-fold to $10^{3}$-fold for mesophilic and xerophilic fungi

Table 2. Prevalence of the predominant fungi in viable spore concentration (\%) and among air samples (\%) collected from cow barns. (CAMNEA = collection of airborne microorganisms on nucleopore filters, estimation and analysis, MALT $=2 \%$ malt extract agar, HAGEM = malt-glucose-rose Bengal agar)

Fungi In concentration In samples
group or genera

\section{CAMNEA}

Mesophilic fungi

Aspergillus

Penicillium

Cladosporium

Acremonium

Yeasts

Xerophilic fungi

Wallemia sebi

Aspergillus

Penicillium

Cladosporium

Absidia

Thermophilic fungi

Aspergillus

Absidia

Penicillium

Paecilomyces

Yeasts

Impactor

Mesophilic fungi

Penicillium

Aspergillus

Yeasts

Sterile mycelia

Cladosporium

Xerophilic fungi

Aspergillus

Penicillium

Sterile mycelia

Cladosporium

Yeasts

$\begin{array}{rr}48 & 91 \\ 34 & 100 \\ 7 & 63 \\ 5 & 34 \\ 4 & 66\end{array}$

Thermophilic fungi

Aspergillus

Yeasts

Sterile mycelia

Penicillium

Mucor

$33 / 42^{a}$

$32 / 28$

$14 / 7^{\mathrm{a}}$

$12 / 14^{a}$

$5 / 8^{a}$

91

100
63

34
66

97

100

97
78

78
19

50

38

16

16
6

a The two values represent the results obtained with the MALT and HAGEM media, respectively. 
Table 3. Prevalence of different fungal genera in the feeding and bedding material samples (\%) used on 32 farms. The superscripts refer to the literature references in which the same fungi were detected in the materials or in the air during the handling of the materials.

\begin{tabular}{|c|c|c|c|c|c|c|}
\hline \multirow[t]{2}{*}{ Fungus } & \multicolumn{6}{|c|}{ Percentage frequency in samples } \\
\hline & $\begin{array}{l}\text { Grain } \\
(N=26)\end{array}$ & $\begin{array}{l}\text { Silage } \\
(N=10)\end{array}$ & $\begin{array}{l}\text { Straw } \\
(N=21)\end{array}$ & $\begin{array}{l}\text { Hay } \\
(N=41)\end{array}$ & $\begin{array}{l}\text { Peat } \\
(\mathbb{N}=4)\end{array}$ & $\begin{array}{l}\text { Wood } \\
\text { bedding } \\
(N=8)\end{array}$ \\
\hline \multicolumn{7}{|c|}{ Mesophilic or thermophilic } \\
\hline Absidia & $15^{14}$ & $20^{14}$ & $33^{14}$ & $49^{14}$ & 一 & $13^{14}$ \\
\hline Acremonium & $4^{6,10}$ & $10^{14}$ & $10^{6}$ & $5^{6,9}$ & - & -14 \\
\hline Alternaria & $8^{10,14}$ & - & $5^{14}$ & $17^{13,14}$ & - & $-^{12,14}$ \\
\hline Aspergillus & $12^{6,11,13,14}$ & $20^{14}$ & $10^{6,11,13,14}$ & $54^{6,9,13-15}$ & - & $50^{6,11,12,14}$ \\
\hline Aureobasidium & $12^{14}$ & - & -14 & $2^{13-15}$ & - & $50^{12,14}$ \\
\hline Cladosporium & $88^{6,10,14}$ & $30^{14}$ & $86^{6,13,14}$ & $71^{6,9,13,14}$ & - & $13^{12,14}$ \\
\hline Fusarium & $77^{10}$ & 20 & 90 & 17 & - & - \\
\hline Mucor & $12^{6,13,14}$ & -14 & $10^{6,13,14}$ & $5^{6,13,14}$ & - & $-6,12,14$ \\
\hline Paecilomyces & $-6,13,14$ & - & $-6,13,14$ & $2^{6,13,14}$ & 50 & $3811,12,14$ \\
\hline Penicillium & $58^{6,10,11,13,14}$ & $50^{14}$ & $33^{6,11,13,14}$ & $78^{6,9,13-15}$ & 100 & $86^{6,11,12,14}$ \\
\hline Rhizopus & $65^{6.14}$ & 10 & $14^{6,11,13,14}$ & $22^{6,13,14}$ & 25 & $50^{6,12.14}$ \\
\hline Trichoderma & -6.14 & 10 & $-6,13,14$ & $17^{6,9,13,14}$ & - & $50^{6,12,14}$ \\
\hline Ulocladium & 4 & - & - & 5 & 一 & - \\
\hline Yeasts & $81^{13,14}$ & $60^{14}$ & $57^{13,14}$ & $56^{13,14}$ & - & $86^{12,14}$ \\
\hline \multicolumn{7}{|l|}{ Xerophilic } \\
\hline Absidia & $38^{14}$ & $20^{14}$ & $14^{14}$ & $15^{14}$ & - & $13^{14}$ \\
\hline Acremonium & 8 & -14 & 10 & - & - & -14 \\
\hline Aspergillus & $35^{11,13,14}$ & -14 & $24^{11,13,14}$ & $20^{13-15}$ & 25 & $38^{11,12,14}$ \\
\hline A. glaugus & $58^{11,13,14}$ & $40^{14}$ & $52^{11,13,14}$ & $95^{13-15}$ & 25 & $63^{11,12,14}$ \\
\hline cladosporium & $92^{14}$ & $20^{14}$ & $95^{13,14}$ & $56^{13,14}$ & - & $13^{12,14}$ \\
\hline Eurotium & - & - & - & $2^{15}$ & - & 13 \\
\hline Monascus & 8 & - & 10 & 5 & - & - \\
\hline Neosartorya & - & - & - & 2 & - & - \\
\hline Penicilliam & $77^{11,13,14}$ & $50^{14}$ & $57^{11,13,14}$ & $73^{13-15}$ & 100 & $100^{11,12,14}$ \\
\hline Phoma & 8 & - & 10 & -15 & - & - \\
\hline Wallemia sebi & $-6,11$ & - & $33^{6}$ & $88^{6}$ & - & 13 \\
\hline Yeasts & $58^{13,14}$ & $30^{14}$ & $48^{13,14}$ & $34^{13,14}$ & 50 & $38^{12,14}$ \\
\hline
\end{tabular}

and even from $10^{3}$-fold to $10^{4}$-fold for thermophilic fungi. The smallest variation (100-fold) was found for the total number of spores. Although the sampling was carried out under similar conditions on each farm, the remarkable variability can be explained by various factors, such as differences in the microbiological quality of feeding and bedding materials, in work manners and devices, and in ventilation equipment and efficiency in the farm buildings between the farms and in the viability of airborne spore between the fungal species.

The geometric means indicated that the xerophilic spore concentrations were higher and thermophilic spore concentrations lower than those of mesophilic fungi. In general, the viable spore concentrations in the barns were at the same level as those measured under corresponding conditions in previous studies $(3,5,6,18)$. Viable spores have been estimated to comprise about $1-25 \%$ of the total spore concentration, depending on the sampling and counting methods and the sampling sites and conditions $(5,6,18)$. In some cases, however, the viability percentage of airborne fungal spores has been as high as $98 \%$ (11). In our study, viable fungal spores consisted of about $1-10 \%$ of the total spore concentrations. However, this estimation is inaccurate because the total number of fun- gal and actinomycete spores was not counted separately and the spore concentrations of viable actinomycetes were not quantified.

The use of a cascade impactor is recommended up to the spore concentration range of $10^{4}-10^{5} \mathrm{cFu} \cdot \mathrm{m}^{-3}$. At higher concentrations, the efficiency and accuracy of the method deteriorate because of overgrowth of the agar plates and the limitation of a sampling time (16). In our study, the spore concentrations sampled with an impactor were approximately in the recommended range. However, one filter sample with a long sampling time gave, on the average, higher spore concentrations than two short-term impactor samples although the impactor samples were taken under conditions in which the spore concentration was assumed to be at its highest. It should also be noted that the results measured with these two methods are not totally comparable because of different sampling times. Spore concentrations determined with the CAMNEA method describe long-term exposure well, while impactor sampling can be used to indicate shortterm peak values provided that spore concentrations are in the recommended range.

The composition of the most common airborne mesophilic and thermophilic fungi, as well as of the 
fungi that occurred to a minor extent, agrees well with the composition reported for fungal flora in the air of cow barns in previous works $(3,5,6)$. Aspergillus, Penicillium, and Cladosporium were the main fungal genera in all of the samples. Aspergillus spp, especially the members of the A glaucus group, have been previously reported to be the most predominant xerophilic fungi in the air of Finnish cow barns (3). The same result was also obtained in this study when NaCl-MALT agar was used as the growth medium. However, the results obtained with DG18 agar revealed that $W$ sebi occurred even more abundantly than Aspergillus spp, comprising almost half of the xerophilic spore concentrations (ie, a magnitude of $10^{3}-10^{6} \mathrm{cFu} \cdot \mathrm{m}^{-3}$. W sebi has been previously found in viable and total spore concentrations of $10^{7} \mathrm{cFu}$ or spores $\cdot \mathrm{m}^{-3}$ in the air of a barley elevator (11). On the other hand, the fungus was observed only in $6 \%$ of the air samples collected from 79 Swedish farms (6). DG18 agar was used in the former study, but not in the latter one. Because DG18 agar favors the growth of slowly growing fungi, such as $W$ sebi, and inhibits the growth of fast growing genera, it is recommended for enumerating xerophilic fungi from dried, low-moisture foodstuffs and from the air in occupational environments where fast growing fungi (eg, Eurotium spp (A glaucus, imperfect state) are present $(19,23)$. W sebi may be an important fungus as an aspect of health effects, because its spores are small $(2.5-3.5 \mu \mathrm{m}$ in diameter) and they usually occur in spore aggregates of less than three spores in the air $(11,24)$. Thus airborne spores of $W$ sebi can easily reach the alveolar region of the lung.

In the impactor samples, more different mesophilic and thermophilic fungal genera were detected on MALT agar $(\mathrm{N}=22)$ than on HAGEM agar $(\mathrm{N}=16)$. Fungal genera, such as Fusarium, Phoma, Gliomastix, Scopulariopsis, Botrytis, Aureobasidium, Papularia, Dimargaris, Acremoniella, Olpitrichum, Wardomyces, Eurotium, and Arthobotrys, were identified only on MALT agar. Correspondingly, Monocillium spp and Staphylotrichum $s p p$ were found only on HAGEM agar. In the case of xerophilic fungi, approximately the same number of fungal genera was detected on DG18 agar $(\mathrm{N}=11)$ as on NaCl-MALT agar $(\mathrm{N}=12)$. As for W sebi, DG18 agar seemed to be a suitable medium for Ascomycetes. In addition, the prevalence of yeasts and sterile mycelia was higher in the impactor samples than in the filter samples. However, generalizations should be avoided in this case, because the effects of the sampling methods and the growth media on the composition of fungal flora cannot be separated.

The same fungal genera were predominant both in the air of the cow barns and in the feeding and bedding materials handled during the air sampling. Table 3 shows that similar fungal flora were detected in the materials in this study as presented in the literature. The results indi- cate that dried hay is the main source of $W$ sebi spores. The same finding was also obtained in a Swedish study (6). However, according to a paper reported in the United States, W sebi did not belong to the main fungi in dried hay (15).

The results also show that Fusarium spp were very common in grain and straw; $77-90 \%$ of the samples contained the fungus. A high prevalence of Fusaria ( $>85 \%$ of the grain samples studied) was also detected in an earlier Finnish report (10). However, the spores of Fusarium spp were only found in concentrations of $10^{2}$ $\mathrm{cFu} \cdot \mathrm{m}^{-3}$ in $34 \%$ of the air samples. A possible reason for this finding is that Fusarium conidia are not necessarily easily released into the air. It has been stated that the discharge of Fusarium conidia is favored by cold air with a high humidity, and conidia typically occur in short-term and explosive peaks in the air (25). In addition, particularly macro-conidia, as large spores (15$90 \mu \mathrm{m} \times 2-7 \mu \mathrm{m})$, settle rapidly in the air (24). Furthermore, the identification of Fusaria can be difficult because only a few growth media favor the sporulation of the fungus (24). However, the detection of Fusaria in agricultural environments is important because Fusarium species may have a significant role as an allergen source and mycotoxin producer $(26,27)$.

\section{Concluding remarks}

The present work indicated that relatively high fungal spore concentrations (up to $10^{7}$ spores $\cdot \mathrm{m}^{-3}$ ) with a large variability and a wide spectra of fungal species originated from feeding and bedding materials in Finnish cow barns. With two sampling and counting methods, different information can be obtained on exposure to microfungi. Cascade impactor sampling with the cultivation method can be used to indicate short-term exposure to airborne spores of different fungal species, while filter sampling combined with the determination of both viable and total spore concentrations is a useful tool for evaluating total exposure to fungi during periods of several hours in highly contaminated environments. The study also revealed that $W$ sebi is a very abundant fungus in hay and in the air of cow barns, while Fusarium spp are common in grain and straw but are not necessarily frequent in the air.

\section{Acknowledgments}

This work was supported by a grant from the Farmers' Social Insurance Institution and the Ministry of Labour. 


\section{References}

1. Lacey J, Lacey ME. Spore concentrations in the air of farm buildings. Trans Br Mycol Soc 1964;47:547_-52.

2. Clark S, Rylander R, Larsson L. Airborne bacteria, endotoxin and fungi in dust in poultry and swine confinement buildings. Am Ind Hyg Assoc J 1983;44:537-41.

3. Kotimaa MH, Husman KH, Terho EO, Mustonen MH. Airborne molds and actinomycets in the work environment of farmer's lung patients in Finland. Scand J Work Environ Health 1984;10:115-19.

4. Crook B, Lacey J. Enumeration of airborne micro-organisms in work environments. Environ Technol Lett 1988;9:515 - 20.

5. Heikkilä P, Kotimaa M, Tuomi T, Salmi T, Louhelainen K. Identification and counting of fungal spores by scanning electron microscope. Ann Occup Hyg 1988;32:241 - 8 .

6. Karlsson K, Malmberg P. Charactrization of exposure to molds and actinomycetes in agricultural dusts by scaming electron microscopy, fluorescence microscopy and the culture method. Scand J Work Environ Health 1989;15:353 - 9.

7. Crook B, Robetson JF, Travers Glass SA, Botheroyd EM, Lacey J, Topping MD. Airborne dust, ammonia, microorganisms, and antigens in pig confinement houses and the respiratory health of exposed farm workers. Am Ind Hyg Assoc $\mathbf{J}$ 1991:52:271—9.

8. Malmberg P, Rask-Andersen A, Rosenhall L. Exposure to microorganisms associated with allergic alveolitis and febrile reactions to mold dust in farmers. Chest 1993;103:1202-9.

9. Gregory PH, Lacey ME. Liberation of spore from mouldy hay. Trans Br Mycol Soc 1963;46:73-80.

10. Ylimäki A, Koponen H, Hintikka E-L, Nummi M, NikuPaavola M-L, Ilus T, et al. Mycoflora and occurrence of Fusarium toxins in Finnish grain. Espoo: Technical Research Centre of Finland, 1979. Scientific publications, no 21.

11. Eduard W, Lacey J, Karlsson K, Palmgren U, Ström G, Blomquist G. Evaluation of methods for enumerating microorganisms in filter samples from highly contaminated occupational environments. Am Ind Hyg Assoc J 1990;51:427-36.

12. Kotimaa MH. Occupational exposure to fungal and actinomycete spores during the handling of wood chips. Grana 1990; $29: 153-6$.

13. Kotimaa MH. Spore exposure arising from stored hay, grain and straw. J Agric Sci Fin 1990;62:285—91.
14. Kotimaa MH, Oksanen L, Koskela P. Feeding and bedding materials as sources of microbial exposure on dairy farms. Scand J Work Environ Health 1991;17:117-22.

15. Sorenson WG, Siegel PD, Olenchock SA. Fungi in aerosols of hay associated with respiratory distress in dairy cattle. Int Biodeterioration Biodegradation 1992;30:353 - 62 .

16. Blomquist G, Ström G, Strömquist L-H. Sampling of high concentrations of airborne fungi. Scand J Work Environ Health 1984:10:109-13.

17. Palmgren U, Ström G, Blomquist G, Malmberg P. Collection of airborne micro-organisms on Nuclepore filters, estimation and analysis - CAMNEA method. J Appl Bacteriol 1986;61 $401-6$.

18. Pasanen A-L, Kalliokoski P, Pasanen P, Salmi T, Tossavainen A. Fungi carried from farmers' work into farm houses. Am Ind Hyg Assoc J 1989;50:631-3.

19. Hocking AD, Pitt JI. Dichloran-glycerol medium for enumeration of xerophilic fungi from low-moisture foods. Appl Environ Microbiol 1980;39:488 - 92

20. Russel BS, editor. Mycology guidebook. Seattle, WA: Mycological Society of America, University of Washington Press, 1974.

21. Terho EO. Micorbiological and serological studies on farmers' lung disease. Kuopio, Finland: University of Kuopio, 1978. Publications of the University of Kuopio, Medicine series original reports, no 1.

22. Andersen AA. New sampler for the collection, sizing, and enumeration of viable airborne particles. J Bacteriol 1958;76: $471-84$.

23. Smid T, Schokkin E, Boleij JSM, Heederik D. Enumeration of viable fungi in occupational environments: a comparison of samplers and media. Am Ind Hyg Assoc J 1989;50:235—9.

24. Samson RA, van Reenen-Hoekstra ES, editors. Introduction to food-borne fungi. Baarn (The Netherlands): Centraalbureal voor Schimmelcultures, 1988.

25. von Wahl P-G, Kersten W. Fusarium and Didymella - neglected spores in the air. Aerobiologia 1991;7:111-7.

26. Frankland AW. Fusarium - a neglected mould. Grana $1983 ; 22: 167-70$

27. Miller JD. Fungi as contaminants in indoor air. Atmos Environ 1992:26A:2163- 72

Received for publication: 22 August 1994 